Utah State University

DigitalCommons@USU

Posters

Materials Physics

$5-14-2012$

\title{
In Situ Surface Voltage Measurements of Dielectrics Under Electron Beam Irradiation
}

Joshua L. Hodges

Utah Sate University

Alec Sim

Utah State University \& Irving Valley College

Justin Dekany

Utah State University

Gregory Wilson

Utah State University

Amberly Evans

Utah State University

JR Dennison

Utah State Univesity

Follow this and additional works at: https://digitalcommons.usu.edu/mp_post

\section{Recommended Citation}

Hodges, Joshua L.; Sim, Alec; Dekany, Justin; Wilson, Gregory; Evans, Amberly; and Dennison, JR, "In Situ Surface Voltage Measurements of Dielectrics Under Electron Beam Irradiation" (2012). 12th Spacecraft Charging Technology Conference 14-18 May, 2012 Kitakyushu Japan. Posters. Paper 6.

https://digitalcommons.usu.edu/mp_post/6

This Poster is brought to you for free and open access by the Materials Physics at DigitalCommons@USU. It has been accepted for inclusion in Posters by an authorized administrator of DigitalCommons@USU. For more information, please contact digitalcommons@usu.edu.

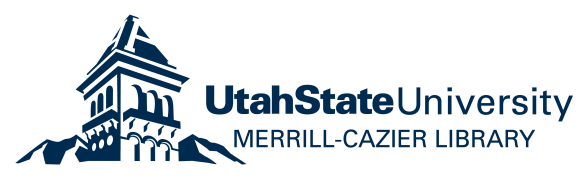




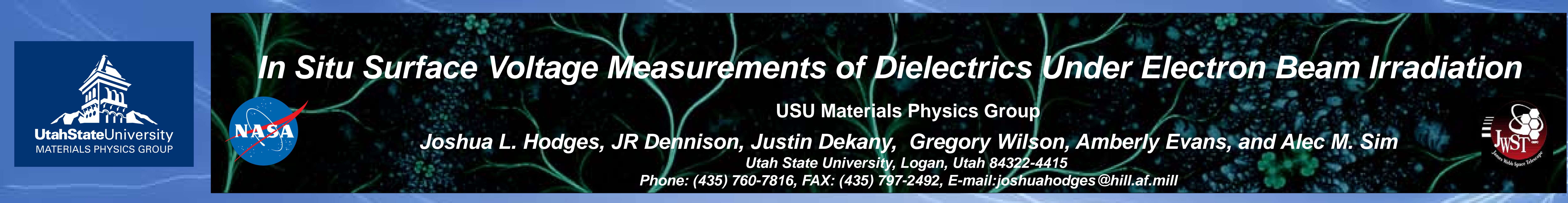

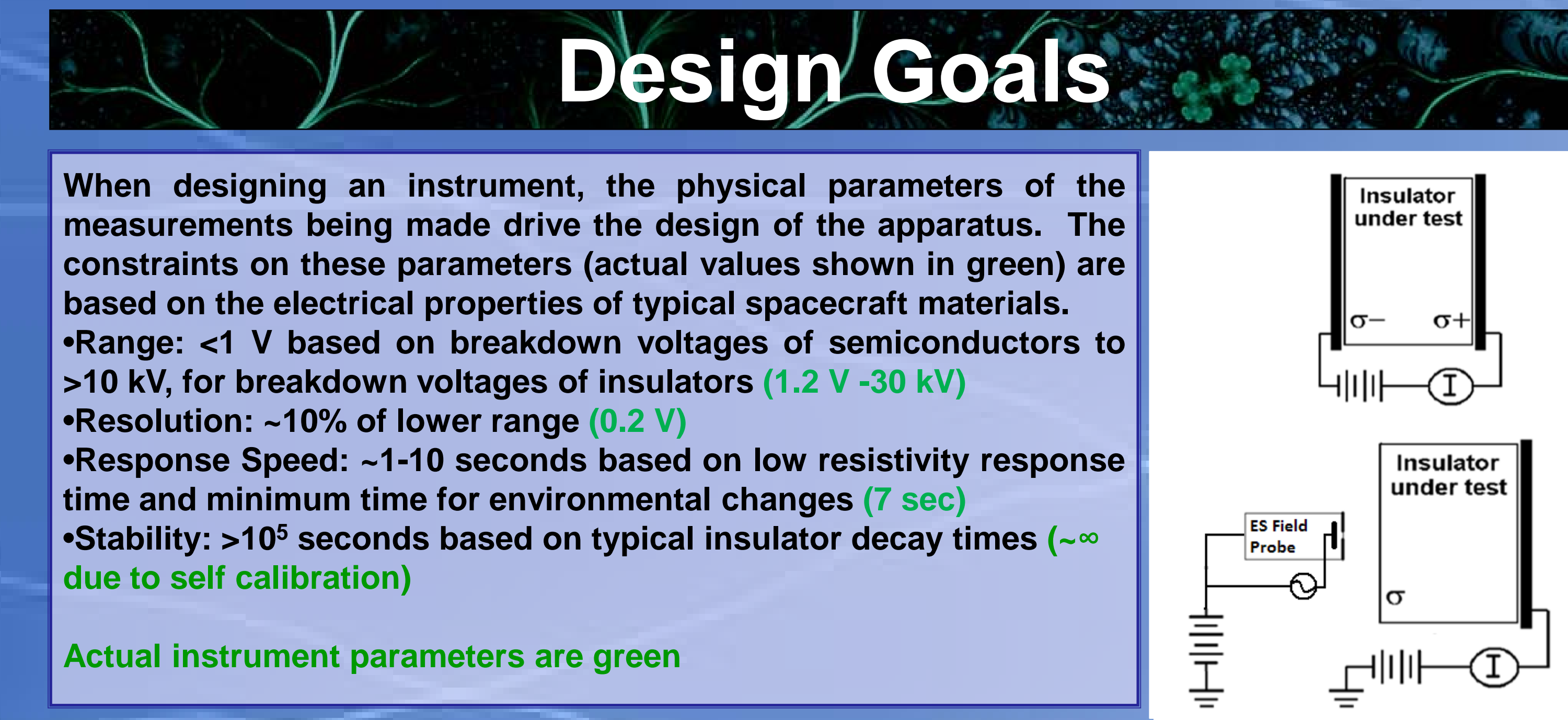

Characterization and Calibration Extensive testing helped develop an understanding of all effects factoring into E.(1), that converts probe voltage to a sample voltage.

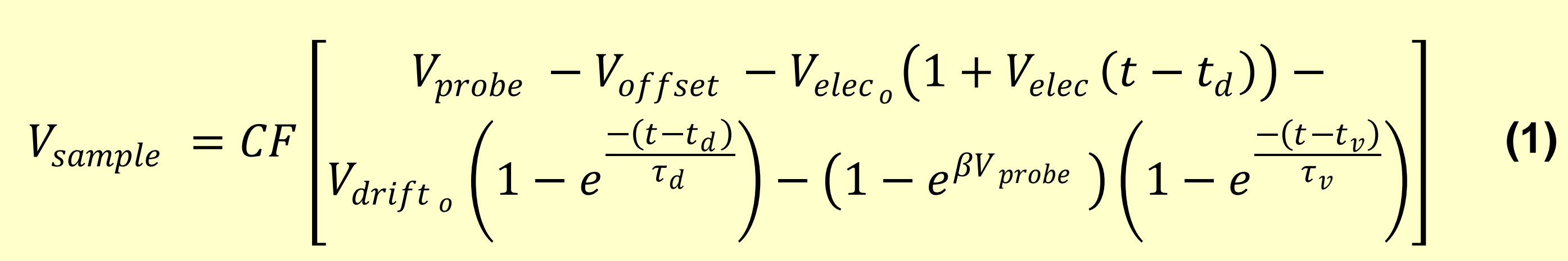
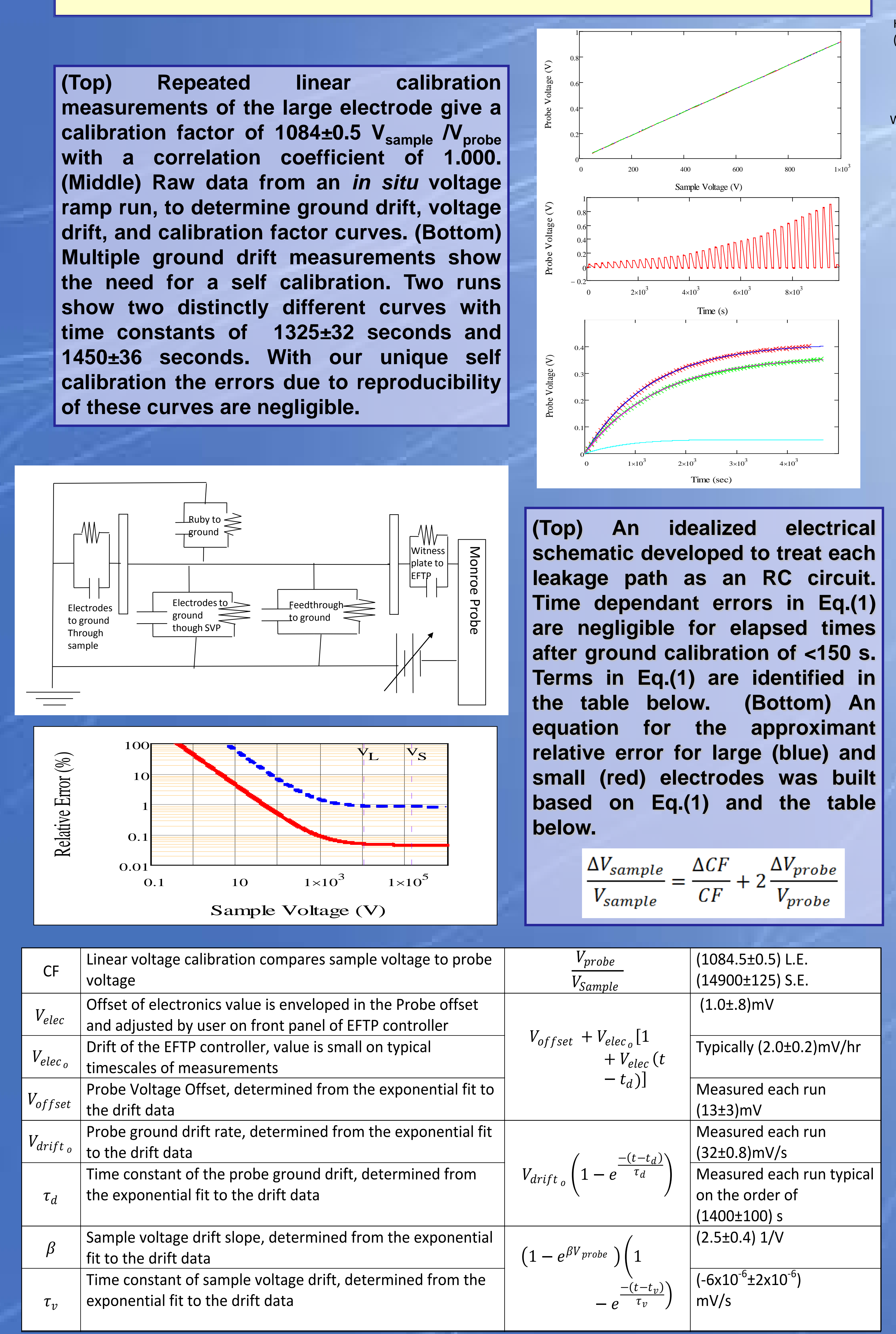
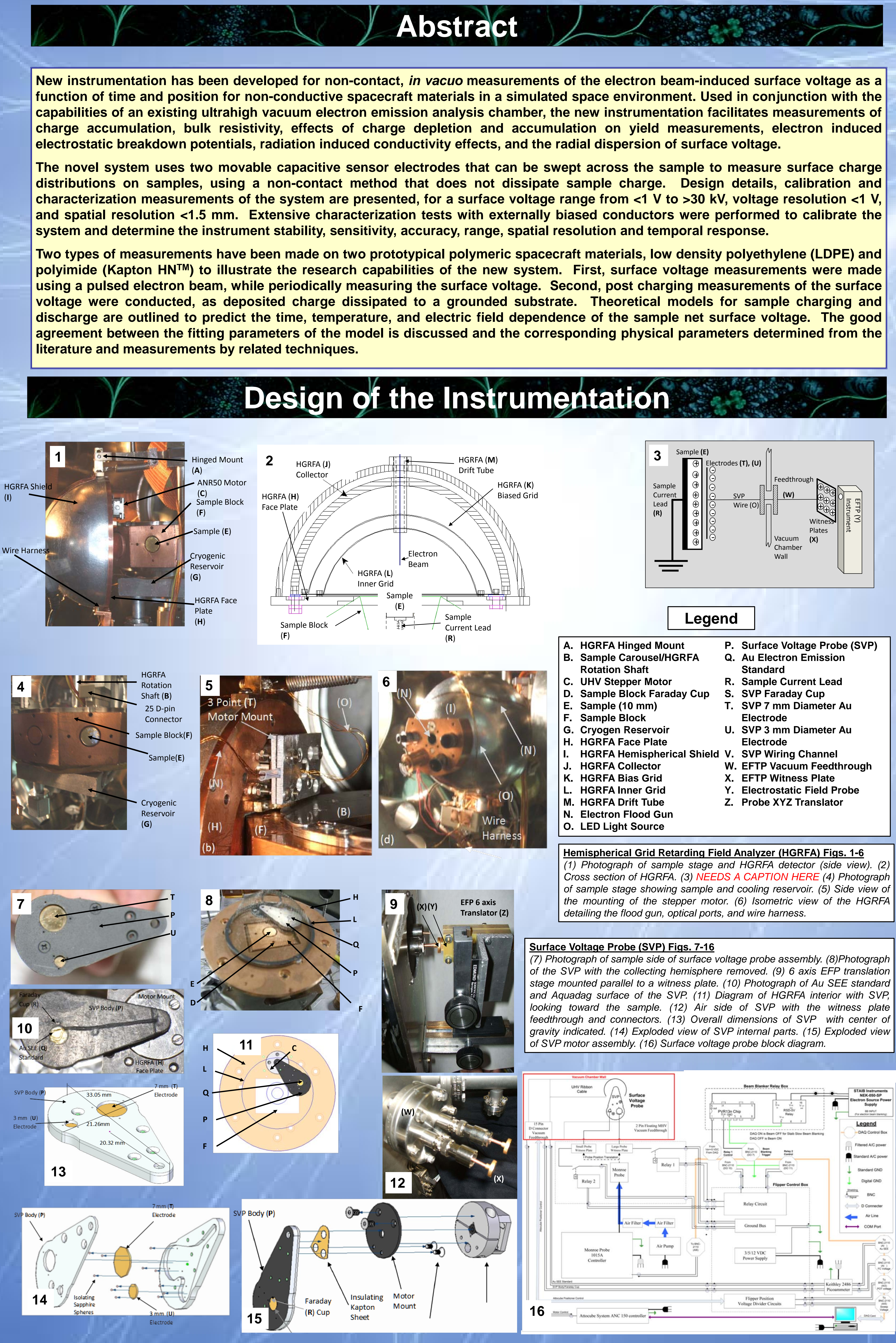

Experimental Applications

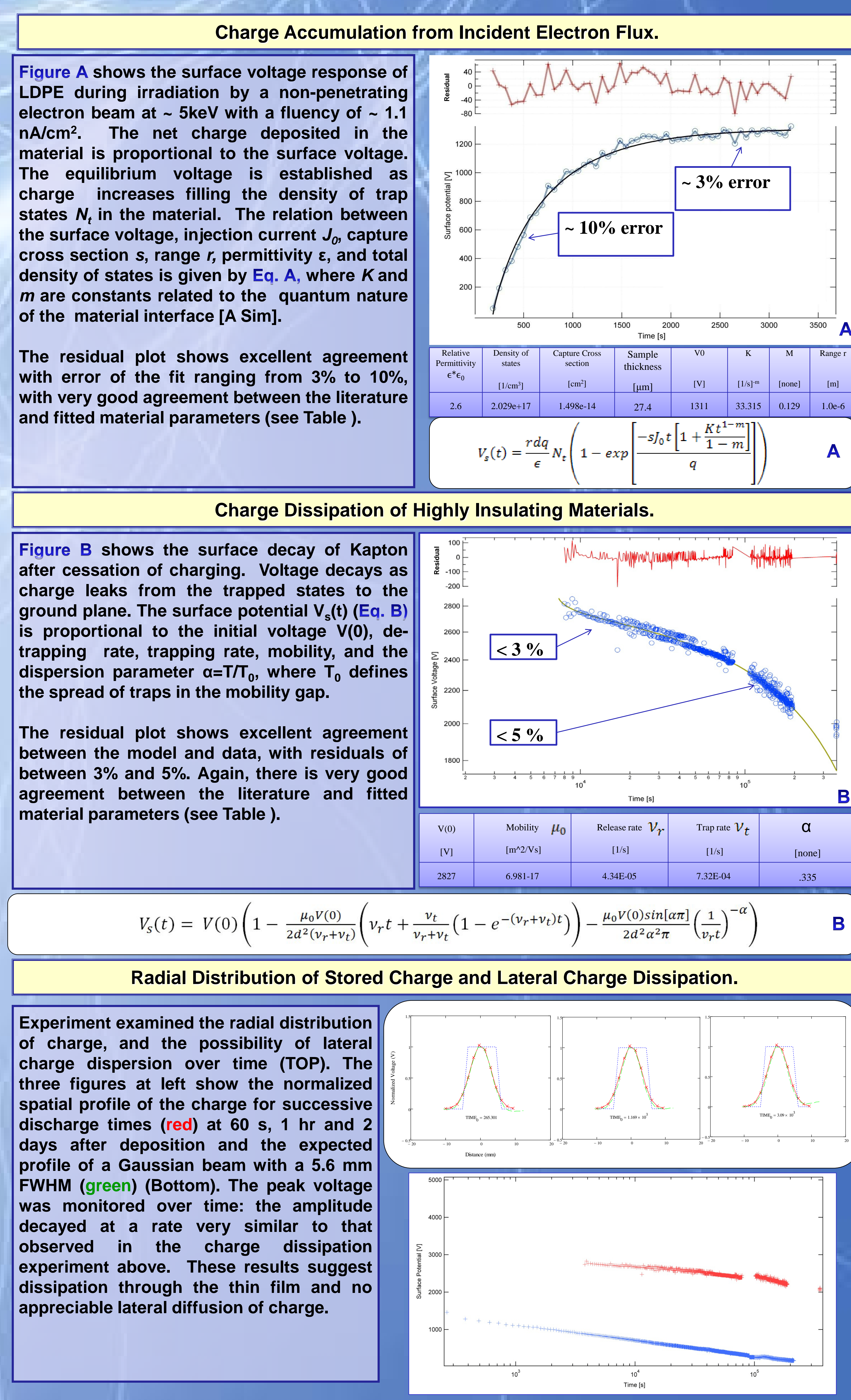

References

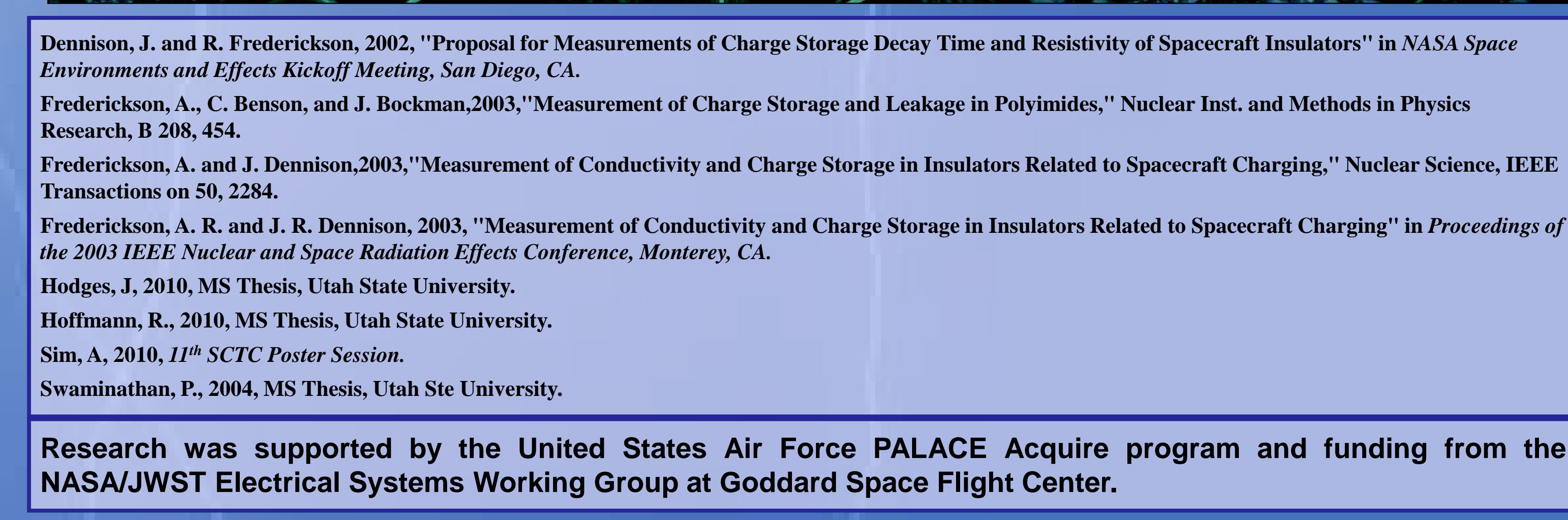

